\title{
VALIDAÇÃO DOS PROCESSOS DE LIMPEZA E DESINFECÇÃO DOS ARTIGOS DE INALOTERAPIA E OXIGENOTERAPIA
}

\author{
[Validation for the cleaning and disinfection process of inhalation \\ and oxygen therapy components]
}

RUBENS GRIEP, Enfermeiro, Graduado pela Universidade Estadual do Oeste do Paraná, Especialista em Desenvolvimento Gerencial e Recursos Humanos pela UNIVEL e em Formação Pedagógica em Educação Profissional na Área da Saúde: Enfermagem pela Universidade Estadual de Maringá UEM/Fiocruz/Escola Nacional de Saúde Pública. Mestre em Engenharia de Produção com ênfase em Psicologia das Organizações pela Universidade Federal de Santa Catarina - UFSC, Pós-graduando em Enfermagem com Ênfase em Centro Cirúrgico pela Universidade Estadual do Oeste do Paraná UNIOESTE. Docente do curso de Administração Hospitalar da União PanAmericana de Ensino - UNIPAN e Enfermeiro da Secretaria Municipal de Saúde de Cascavel. Rua Cristóvão Colombo n ${ }^{\circ} 519$, apto 501, bloco 01, Pioneiros Catarinenses CEP 85.805-510, Cascavel - Paraná. Telefones: (45) 226-8539 e 9971-7929, e-mail rgriep@uol.com.br

MARISTER PICOLLI, Enfermeira, Mestre em Enfermagem Fundamental pela Escola de Enfermagem de Ribeirão Preto - USP, docente do Colegiado de Enfermagem e Coordenadora do Curso de Especialização em Enfermagem com ênfase em Centro Cirúrgico da Universidade Estadual do Oeste do Paraná - UNIOESTE. 


\title{
VALIDAÇÃO DOS PROCESSOS DE LIMPEZA E DESINFECÇÃO DOS ARTIGOS DE INALOTERAPIA E OXIGENOTERAPIA
}

\begin{abstract}
RESUMO: Apresenta-se uma revisão bibliográfica sobre os principais aspectos relacionados aos processos de limpeza e desinfecção de artigos de inaloterapia e oxigenoterapia. A leitura dos textos de apoio, documentos e literatura específica possibilitaram a compreensão dos principais elementos a serem considerados na validação destes processos bem como apontam para a necessidade de reestruturação do Centro de Material e Esterilização como requisito fundamental para a melhoria da qualidade nos Estabelecimentos Assistenciais de Saúde.
\end{abstract}

PALAVRAS-CHAVE: limpeza e desinfecção de artigos; validação de processo; qualidade em saúde.

\section{VALIDATION FOR THE CLEANING AND DISINFECTION PROCESS OF INHALATION AND OXYGEN THERAPY COMPONENTS}

\begin{abstract}
A bibliographic revision of the main aspects related to the cleaning and disinfection processes of inhalation and oxygen therapy components is presented here. The reading of supporting text, documents and specific literature make the understanding of the main elements to be considered possible when validating these processes, and also point to the restructuring need of the Components and Sterilization Center (Centro de Material e Esterilização) as a fundamental requirement for the quality improvement at the Health Assistance Establishments (Estabelecimentos Assistenciais de Saúde).
\end{abstract}

KEYWORDS: Cleaning and disinfection of components; validation process; health quality 


\section{INTRODUÇÃO}

Os avanços científicos e tecnológicos percebidos nas últimas décadas vem contribuindo significativamente na melhoria dos indicadores de qualidade da assistência à saúde prestada pelos Estabelecimentos Assistenciais de Saúde (EAS) no Brasil, possibilitando, entre outras modalidades, o atendimento ambulatorial e domiciliar de patologias consideradas simples. Neste contexto, observamos ótimos resultados terapêuticos, mas também um aumento dos riscos reais de aquisição de infecções e outras doenças relacionadas a (re)utilização de artigos médico-hospitalares.

Apesar de a maioria das infecções hospitalares, aqui entendidas como complicações infecciosas decorrentes de procedimentos diagnósticos e terapêuticos realizados dentro dos EAS, serem causadas pelos próprios microrganismos da microbiota do indivíduo, associados a queda dos mecanismos de defesa locais e sistêmicos, as infecções de origem exógena merecem a atenção dos profissionais da área da saúde. A utilização de normas técnicas cientificamente estabelecidas e regulamentadas pela Agência Nacional de Vigilância Sanitária (ANVISA), devem servir de base para a elaboração de rotinas a serem recomendadas como critérios mínimos de controle de qualidade nos processos de limpeza, desinfecção e esterilização de artigos médico-hospitalares. Muito tem se discutido em relação a validação dos 
processos de esterilização de artigos nos EAS, sendo que esta prática já esta regulamentada pela ANVISA e é adotada, via de regra, por todos os serviços que executam tal procedimento, visando garantir a adequabilidade, segurança e efetividade dos processos de esterilização. Neste contexto, discute-se a relevância dos procedimentos de limpeza e desinfecção na garantia dos processos de esterilização ao qual o artigo será submetido, e com menos ênfase, a validação destes processos, principalmente em artigos que não serão submetidos a esterilização.

Dentre os artigos médico-hospitalares mais utilizados, encontramos os dispositivos para macro e micronebulização terapêutica a base de oxigênio e/ou ar estéril medicinal, procedimento comumente denominado de inaloterapia e/ou oxigenoterapia. Estes artigos são confeccionados em material plástico termo-sensível, sendo que, após o uso, são submetidos aos processos de limpeza e desinfecção. Apesar das intensas discussões em relação as rotinas específicas para o processamento destes artigos, os EAS vem encontrando inúmeras dificuldades na operacionalização destas, incluindo-se as questões relacionadas ao controle de qualidade e validação dos procedimentos realizados.

Para que possamos iniciar qualquer discussão neste sentido, torna-se claro a necessidade de classificar os artigos a serem processados, identificar os principais microorganismos encontrados nestes artigos, selecionar os métodos de limpeza e os níveis de desinfecção desejados para cada um, considerando-se primariamente o risco potencial de aquisição de infecção associado ao uso destes como premissas para a validação destes processos, 
uma vez que a avaliação de rotina é subjetiva, por não ser possível mensurar o "bioburden" de cada artigo a cada procedimento de limpeza e desinfecção.

Este estudo tem como objetivo propor através da revisão bibliográfica, uma metodologia específica para a validação dos processos de limpeza e desinfecção dos artigos de inaloterapia e oxigenoterapia utilizados nos EAS, com vistas a garantir sua adequabilidade e segurança, contribuindo de maneira efetiva para o controle das infecções hospitalares e de doenças transmissíveis de alta prevalência no país (Tuberculose, Hepatite B).

\section{PROCEDIMENTOS METODOLÓGICOS}

Este estudo constitui-se em uma pesquisa bibliográfica e documental "desenvolvida a partir de material já elaborado, constituído principalmente de livros e artigos científicos" (Gil, 1996, p.48). Para a realização deste estudo, utilizamos as fases descritas por Gil (1996) sendo elas: determinação do objetivo; elaboração do plano de trabalho; identificação das fontes; localização e obtenção do material; leitura do material; tomada de apontamento; confecção de fichas e redação do trabalho.

A identificação das referências bibliográficas foi feita por meio do sistema de fichário da Biblioteca da Universidade Estadual do Oeste do Paraná (UNIOESTE). As fontes bibliográficas consultadas incluíram livros textos, documentos do Ministério da Saúde e Agência Nacional de Vigilância Sanitária, bem como os Descritores em Ciências da Saúde (DeCS-LILACS) elaborados pela Biblioteca Virtual em Saúde (BIREME). Os unitermos utilizados foram: 
limpeza e desinfecção de artigos, validação de processo e qualidade em saúde. O levantamento bibliográfico foi feito desde 1980 até 2003, excluindo as pesquisas realizadas com soluções de limpeza e desinfetantes não regulamentadas pelo Ministério da Saúde e Agência Nacional de Vigilância Sanitária.

De posse do material bibliográfico compilado, iniciamos a pesquisa exploratória com a finalidade de identificar e separar o referencial que atendesse aos objetivos propostos, sem no entanto nos preocuparmos com a sistematização das informações. A seguir, após leitura analítica do material selecionado, identificamos as idéias centrais através de anotações, organizando-as seguindo o critério de relevância com vistas a uma síntese posterior. Cabe ressaltar que após a organização dos conteúdos, optamos em apresentá-los na seqüência em que são abordados na literatura: classificação dos artigos médico-hospitalares, limpeza e desinfecção, insumos e validação dos processos de limpeza e desinfecção.

\section{FUNDAMENTAÇÃO TEÓRICA}

\subsection{CLASSIFICAÇÃO DOS ARTIGOS MÉDICO HOSPITALARES}

A classificação elaborada por Spauding em 1968 (TABELA 01), deve ser considerada uma diretriz, merecendo julgamento crítico em relação à diversidade de situações identificadas no contexto dos EAS. A opção para a escolha do tipo de processamento de um artigo depende primariamente do 
risco potencial de aquisição de infecção associado ao uso deste. Assim sendo, a manipulação de tecidos estéreis exige artigos esterilizados; a manipulação de mucosas íntegras exige minimamente desinfecção e a manipulação em pele íntegra ou de artigos que não entram em contato com o paciente requer, no mínimo, a limpeza.

TABELA 01 - Classificação de Spauding

\begin{tabular}{|l|l|}
\hline Artigos Críticos & $\begin{array}{l}\text { São assim denominados em função do alto risco de } \\
\text { infecção, se estiverem contaminados com qualquer } \\
\text { microorganismo ou esporos. São artigos que entram em } \\
\text { contato com tecidos ou tratos estéreis. }\end{array}$ \\
\hline Artigos Semicríticos & $\begin{array}{l}\text { São aqueles que entram em contato com a pele não íntegra } \\
\text { e membranas mucosas. }\end{array}$ \\
\hline Artigos Não-críticos & São os artigos que entram em contato com a pele íntegra. \\
\hline
\end{tabular}

Fonte: Baseado em Brasil (2001, p. 13).

Além da classificação de Spauding, os artigos médico-hospitalares são divididos de acordo com suas características físicas constituintes em termoresistentes e termo-sensíveis. A escolha dos procedimentos a serem adotados e dos métodos ideais deve então levar em conta a finalidade a que se destina o artigo e a característica física deste, optando-se por aqueles que sejam efetivos, oferecem segurança e economia (GUIA DE ENFERMEIROS, 2000).

\subsection{LIMPEZA E DESINFECÇÃO}

Segundo Padoveze e Delmonte (1999), limpeza é a remoção mecânica de sujidade. É realizada pela aplicação de energia mecânica (fricção), química (soluções detergentes, desincrostantes ou enzimáticas) ou térmica, e tem como 
objetivo reduzir a carga microbiana, remover contaminantes de natureza orgânica ou inorgânica e manter a vida útil do artigo.

O emprego de ação mecânica e soluções adequadas aumentam a eficiência da limpeza. Se um artigo não for adequadamente limpo, dificultará o processo de desinfecção e/ou esterilização, reduzindo a probabilidade de eliminação dos microorganismos ao final do processo, principalmente quando o "bioburden" for muito alto. Por este motivo, a limpeza dos artigos torna-se extremamente importante para garantir a segurança do processo ao qual o artigo será submetido, uma vez que o sucesso da desinfecção/esterilização depende da carga microbiana presente inicialmente no artigo.

De acordo com SOBECC (1999-2001), a seleção dos métodos de limpeza e a elaboração de normas e rotinas para os métodos a serem empregados é fundamental para a garantia do processo, devendo-se levar em consideração o método mais adequado ao tipo de material utilizado, considerando-se as necessidades e recursos disponíveis no EAS. Além destes aspectos, o método deve ser compatível com o artigo a ser processado, objetivando uma limpeza escrupulosa e meticulosa, procurando-se desenvolver para cada tipo de artigo a melhor maneira de executar esta tarefa. Segundo o Guia de Enfermeiros (2000), entre os métodos disponíveis, encontramos: a) Limpeza Manual, realizada manualmente para a remoção da sujidade através do uso de escova, detergente e água; b) Limpeza Mecânica, procedimento automatizado para a remoção de sujidade por meio de lavadoras com ação física e química. 
A rotina de limpeza deverá ser elaborada, considerando-se os métodos disponíveis e os insumos padronizados pelo EAS. A equipe de enfermagem deverá conhecer todos os mecanismos de segurança a serem utilizados, não só em relação a saúde ocupacional e prevenção de acidentes (Equipamentos de Proteção Individual), mas também àqueles relacionados aos cuidados com a conservação dos artigos e diminuição dos riscos ambientais.

Outra etapa importante a ser normatizada diz respeito a secagem dos artigos que serão submetidos ao processo de desinfecção. $O$ uso de compressas limpas e de luvas de procedimento é imprescindível para que os artigos não recebam nova carga de sujidade, mesmo que não aparente. Nesta fase, a inspeção e verificação do artigo deve preceder a etapa de desinfecção, visando detectar falhas no processo de limpeza e defeitos estruturais dos artigos.

De acordo com Brasil (2001), o processo de desinfecção de artigos médico-hospitalares subdivide-se em três níveis, sendo que estes devem corresponder diretamente a classificação dos artigos a serem processados: 1) Desinfecção de alto nível; 2) Desinfecção de nível intermediário e 3) Desinfecção de baixo nível.

O conhecimento adquirido sobre a transmissão de doenças e o estabelecimento de precauções básicas faz com que se considere potencialmente contaminado todo e qualquer instrumento ou material que tenha tido contato com matéria orgânica, independente do seu grau de sujidade aparente (BRASIL, 2001). A desinfecção dos artigos de inaloterapia e oxigenoterapia poderá ser feita por métodos físicos, químicos e físico-químicos. 
Considerando-se as particularidades dos EAS e tendo como objetivo abranger o maior número de serviços, estaremos discutindo aspectos relacionados a desinfecção química com o uso do Hipoclorito de Sódio, uma vez que este vem sendo utilizado em larga escala.

Existe controvérsia em relação a concentração dos desinfetantes a serem utilizados, de acordo com Brasil (2001), os artigos de inaloterapia e oxigenoterapia devem ser submetidos a desinfecção de médio nível, tendo-se como método de primeira escolha o uso de Hipoclorito de Sódio na concentração de $200 \mathrm{ppm}$, ou seja, de $0,02 \%$ a $0,5 \%$ de Cloro Ativo por 60 minutos, dispensando-se o enxágüe. Fernandes et al. (2000) recomenda o uso de Hipoclorito de Sódio a 1\% por 30 minutos com rotina de enxágüe abundante após. Para fins deste artigo, estaremos utilizando a primeira concentração citada, como critério estabelecidos pela Secretaria de Assistência à Saúde/Divisão de Controle de Infecção Hospitalar (BRASIL, 2001).

Durante o processo de desinfecção, devem ser consideradas as seguintes questões: 1) Área restrita para realização de desinfecção em sistema aberto (manual/química); 2) Validade do desinfetante após a diluição; 3) Conservação do Hipoclorito de Sódio em recipientes foscos; 4) Limpeza e secagem prévia dos artigos; 5) Imersão total de todos os artigos e tubulações; 6) Uso de EPI's apropriados; 7) Cuidados para não recontaminar os artigos durante o processo, e 10) Acondicionar em recipiente estéril ou desinfetado até o momento do embalo.

\subsection{EMBALAGEM E ARMAZENAMENTO}


Todo artigo desinfetado pronto para o uso deverá ser acondicionado em embalagem criteriosamente selecionada para a segurança do processo. Muitos EAS utilizam apenas recipientes plásticos com tampa, o que inviabiliza a manutenção das condições mínimas necessárias à utilização destes artigos, principalmente após o envio para as Unidades de Internação.

Segundo o Guia de Enfermeiros (2000) as principais características do sistema de embalagem são: a) Manter a integridade da embalagem em condições de estocagem; b) Manter a integridade da selagem e ser à prova de violação; c) Resistir a gotículas de água; d) Ser isenta de furos; e) Ser livre de resíduos tóxicos como corantes, alvejantes e amido; f) Evitar a liberação de partículas; g) Ser barreira microbiana; h) Ser compatível com as dimensões, peso e configurações do artigo, e i) Apresentar relação custo-benefício favorável.

Dentre as possibilidades identificadas, a embalagem plástica lacrada através do uso de uma termo-seladora vem demonstrando sua aplicabilidade pelo baixo custo agregado ao processo e principalmente pelo fato de ser transparente, o que facilita a identificação dos artigos.

Com a finalidade de diminuir o retrabalho e assegurar para o usuário o fornecimento de um artigo sem risco de contaminação e em perfeitas condições de uso, algumas práticas são recomendadas para o empacotamento: a) Lavar as mãos antes de iniciar a atividade; b) Manter os artigos desinfetados em recipiente estéril; c) Realizar desinfecção com álcool a $70 \%$ na bancada de trabalho; d) Preparar a bancada com os materiais 
necessários para o embalo dos artigos, e e) Utilizar avental e luvas estéreis bem como gorro durante a execução da atividade.

Além dos cuidados durante todas as fases do processo, os artigos embalados deverão receber identificação externa, contendo dados gerais de identificação do EAS, número de lote do processo ao qual o artigo foi submetido, data da desinfecção e de validade do processo.

Após a embalagem dos artigos, os mesmos deverão ser armazenados em local adequado, de modo a evitar riscos de recontaminação, favorecer a movimentação e identificação rápida e fácil dos artigos.

Segundo Cardo e Drake (1996) e Pugliese e Honstiger (1992), algumas características recomendadas para a área de armazenagem devem ser seguidas, sendo que estas não diferem daquelas preconizadas para a armazenagem de artigos esterilizados: a) A arquitetura deve ser elaborada de modo a limitar o tráfego, facilitar a identificação de itens, promover a limpeza e proteger os pacotes; b) Manter a temperatura entre $18^{\circ}$ e $22^{\circ} \mathrm{C}$ e a umidade relativa entre 35\% a 50\%; c) As prateleiras devem apresentar distância de no mínimo $20 \mathrm{~cm}$ do piso, $5 \mathrm{~cm}$ das paredes e $45 \mathrm{~cm}$ do teto; d) O local de estocagem de artigos deve ser distante de fonte de água, janelas abertas, portas, tubulações expostas e drenos, e e) A constituição das prateleiras pode ser de aço inoxidável, cestos aramados de aço inoxidável, fórmica tratada e plástico rígido.

Além destas questões, algumas práticas são recomendadas, incluindose a manipulação cuidadosa e menor possível dos artigos, a inspeção periódica para verificação de qualquer degradação, o estabelecimento de uma 
rotina de limpeza da área de estoque bem como a guarda e distribuição dos artigos em ordem cronológica de seus lotes.

\subsection{INSUMOS}

De acordo com o Guia de Enfermeiros $(2000,15)$, todos os produtos que contenham em sua formulação tensoativos cuja finalidade é limpar por meio da redução de tensão superficial da água assim como da dispersão e suspensão da sujidade são considerados detergentes. Ainda segundo o guia, a propriedade de dispersão é definida como a "quebra de partículas de sujidade em partículas bem menores" e a propriedade de suspensão "consiste em manter em solução estas partículas sólidas, finamente divididas, e prevenir sua aglutinação". Algumas substâncias como os coadjuvantes, substâncias menores (anti-redepositante, antioxidante, preservantes, corantes, enzimas, etc.) e materiais inertes fazem parte da composição dos detergentes, e tem como finalidade, dispersar a sujidade em partículas finíssimas sem que estas se prendam a superfície que está sendo limpa bem como balancear a formulação de um detergente, adequando-o a sua finalidade.

Existem diferentes tipos de detergentes disponíveis no mercado e regulamentados pela ANVISA, entre os principais, destacam-se os Detergentes Aniônicos, os Catiônicos e os Não lônicos. Além destes, outra inovação tecnológica são os Detergentes Enzimáticos, compostos por enzimas (protease, amilase e lipase) que promovem a limpeza pela ação de decomposição do sangue e fluídos corpóreos aderidos aos artigos. 
Os desinfetantes ou germicidas de ação intermediária são agentes químicos capazes de destruir bactérias, fungos e vírus em um intervalo de tempo operacional. Estes agentes diferem dos esterilizantes químicos por não destruírem esporos e não serem ativos contra todas as espécies de vírus. As soluções desses germicidas devem ser formuladas com detergentes adequados, em obediência ao conceito de desinfecção e limpeza simultâneas (GUIA DE ENFERMEIROS, 2000).

Como critérios na escolha dos desinfetantes, deve-se satisfazer algumas exigências operacionais como a manutenção de atividade bacteriana, fungicida e viruscida em presença de matéria orgânica e do grau de pureza da água; exercer simultaneamente ação de limpeza e desinfecção; manter ação residual; não oxidar metais e não alterar plásticos.

A Portaria $n^{\circ} 15$ de 1988 do Ministério da Saúde estabelece os seguintes princípios ativos para os desinfetantes de artigos hospitalares: Aldeídos (Formaldeído/Glutaraldeído); Fenólicos (Fenol Sintético); Quaternário de Amônio; Compostos Orgânicos Liberadores de Cloro Ativo; Compostos Inorgânicos Liberadores de Cloro Ativo (Hipoclorito de Sódio, Cálcio e Lítio); lodo e derivados; Álcoois (Álcool Isopropílico e Álcool Etílico 70\%); Glicois; Biguanidas e Peróxidos (BRASIL, 2001).

\subsection{VALIDAÇÃO DOS PROCESSOS DE LIMPEZA E DESINFECÇÃO}

De acordo com Bueno (1996, p. 668), o termo validação é definido como "ato de validar; legalização; legitimação". No contexto das instituições de 
saúde, o termo busca definir o processo por meio do qual se tornam legítimas as etapas relacionadas ao processamento de artigos médico-hospitalares (limpeza, desinfecção e/ou esterilização), para garantir que estas sejam realizadas sempre da mesma forma, com a mesma qualidade. Segundo Guia de Enfermeiros (2000, p. 55), "A validação compreende o conjunto de várias etapas denominadas qualificação, com certificação da adequabilidade dos pontos avaliados". Para SOBECC (1999-2001, p. 28 apud PINTER, 1999), "Validação é um conjunto de medidas que atestam que um determinado processo faz o que se propõe a fazer. Com a implantação do processo de validação nas instituições, passou-se a conhecer, controlar e confiar mais nos equipamentos". De maneira geral, o termo validação tem se tornado usual naqueles Estabelecimentos de Saúde que buscam garantir o controle das infecções hospitalares relacionadas ao uso de artigos médico-hospitalares reprocessáveis, sem deixar de considerar os aspectos relacionados a saúde ocupacional da equipe interdisciplinar atuante no Centro de Material e Esterilização (CME).

Para que qualquer processo possa ser considerado validado, todas as etapas devem ser analisadas de forma crítica, envolvendo princípios de morte ou redução de carga microbiana; o significado dos termos 'limpeza' e 'desinfecção', bem como o conhecimento das características dos equipamentos e soluções utilizadas nestes processos.

O estabelecimento de um protocolo de validação dos processos de limpeza e desinfecção de artigos médico-hospitalares deve ser elaborado tendo como base, os princípios gerais estabelecidos para a validação do processo de 
esterilização, devendo assegurar que o processo foi adequadamente validado. Segundo SOBECC (1999 - 2001), os principais aspectos a serem considerados são: Identificação do processo a ser validado; especificação dos artigos utilizados no processo; objetivos e critérios para determinar se a validação foi bem sucedida; extensão e duração da validação; equipamentos utilizados no processo; operadores envolvidos no processo; identificação dos instrumentos acessórios para a mensuração do processo; descrição completa do processo; parâmetros do processo a ser monitorado e métodos de controle da monitorização, e critérios para revalidação.

De acordo com Guia de Enfermeiros (2000), o processo de validação da esterilização por vapor saturado sob pressão divide-se didaticamente em qualificação do projeto, qualificação da instalação dos equipamentos, qualificação da operação dos equipamentos, e qualificação do desempenho do equipamento.

Para os processos de limpeza, sugere-se a avaliação subjetiva, por não ser possível mensurar o "bioburden" de cada artigo a cada procedimento, neste sentido, torna-se relevante elaborar rotinas e procedimentos escritos envolvendo o manuseio dos equipamentos, a diluição e utilização de detergentes e a inspeção visual criteriosa após o processamento.

Em relação a validação do processo de desinfecção, sugere-se a utilização de um integrador químico que muda de cor quando ocorre o processo efetivo de termo-desinfecção em temperatura de $93^{\circ} \mathrm{C}$ a 10 minutos.

De maneira geral, a validação deve ser entendida como um processo contínuo, incluindo o treinamento e reciclagem do pessoal, tendo como 
objetivo, demonstrar que o processo continuará sendo reproduzido mediante condições normais de operação.

\section{RESULTADOS E DISCUSSÕES}

De acordo com o Guia de Enfermeiros (2000), todas as atividades, rotinas e procedimentos relacionadas ao processamento de artigos médicohospitalares devem ser registradas de forma detalhada, tendo como objetivo a padronização dos processos, permitindo uniformidade, economia, qualidade e viabilizando o rastreamento nos casos de intercorrências.

Um sistema de registro possibilita o acompanhamento de todas as fases dos processos de limpeza e desinfecção, contribuindo significativamente na identificação de falhas em cada uma das etapas, sendo um importante instrumento na validação destes processos.

Como não é possível avaliar o "biodurden" de cada artigo que será submetido a limpeza e a desinfecção, acreditamos que a sistematização dos procedimentos deverá ocorrer após a análise dos diferentes fatores que poderão interferir na qualidade dos processos, neste sentido, a que se considerar os parâmetros físicos e microbiológicos da água e sua relação com os insumos padronizados na instituição; o padrão de tráfego definido para cada uma das etapas; as normas específicas de diluição dos detergentes e/ou desinfetantes bem como aspectos comportamentais ligados ao desempenho da equipe de enfermagem. 
Sugerimos que após a padronização dos insumos pela CCIH e Chefia do CME, sejam estabelecidos protocolos com orientações claras em relação a diluição, conservação e tempo de validade das soluções. Após esta etapa, deve-se investir em adequações da estrutura física, respeitando-se o preconizado pela $\operatorname{RDC} n^{\circ} 50$ de 2002, incluindo-se neste momento uma análise detalhada do fluxo de entrada e saída de artigos e da equipe atuante no setor.

Uma vez sanadas as deficiências, deve-se submeter artigos contaminados aos processos de limpeza e desinfecção, avaliando-se através da realização de culturas diretas em amostras devidamente selecionadas, o crescimento bacteriano.

A partir deste momento, valida-se as normas e rotinas estabelecidas e adota-se um cronograma mensal para revalidação dos processos através de culturas periódicas, realizadas de forma aleatória entre os artigos. Neste caso específico, o tempo de validade dos artigos após o embalo deverá ser de sete dias até que este período seja expandido com a análise individual de cada artigo e a realização de culturas seqüenciais $\left(7^{\circ}, 14^{\circ}, 21^{\circ}\right.$ e $28^{\circ}$ dia do processo).

Os artigos desinfetados poderão permanecer em estoque, desde que consideradas as questões discutidas neste artigo, por um período de até trinta dias, após cultura negativa nas amostras. Cabe a $\mathrm{CCIH}$ e a Chefia do $\mathrm{CME}$ avaliarem a necessidade desta expansão na validade dos artigos (de 7 para 30 dias), considerando entre outros fatores, a alta rotatividade dos itens específicos de inaloterapia e oxigenoterapia. 
Um sistema de registro adaptado para os processos de limpeza e desinfecção como subsídio para a avaliação subjetiva da eficácia destes processos deverá considerar, entre outros, as seguintes informações:

TABELA 02 - Check Lista de Limpeza e Desinfecção

$$
\begin{aligned}
& \text { Centro de Material e Esterilização } \\
& \text { CHECK LIST LIMPEZA E DESINFECÇÃO } \\
& \text { Artigos de Inaloterapia e Oxigenoterapia }
\end{aligned}
$$

\begin{tabular}{|c|c|c|}
\hline \multicolumn{3}{|l|}{ Dados de Identificação } \\
\hline \multicolumn{3}{|c|}{$\begin{array}{l}\text { Tipo de artigo: } \square \text { Inaloterapia } \square \text { Oxigenoterapia } \square \text { Prolongamentos } \square \text { Circuitos } \\
\text { Unidade/Setor de Origem: }\end{array}$} \\
\hline $\begin{array}{l}\text { 1. Relativo ao material/artigo } \\
\text { Integridade estrutural preservada? } \\
\text { Presença de matéria orgânica? } \\
\text { Recebido em containeres fechados? } \\
\text { Misturados com outros artigos? } \\
\text { 2. Relativo ao procedimento de limpeza } \\
\text { Limpeza manual com água e sabão? } \\
\text { Limpeza mecânica em lavadora? } \\
\text { Utilização de recipientes específicos? } \\
\text { Utilização de esponja específica? } \\
\text { Contato dos artigos com a cuba ou bancada? } \\
\text { Secado com compressa limpa e exclusiva? } \\
\text { Acondicionado em recipiente limpo e seco? } \\
\text { Uso de luvas de procedimento limpas e desinfetadas? } \\
\text { 3. Relativo ao procedimento de desinfecção } \\
\text { Materiais limpos e secos? } \\
\text { Identificação da solução com data e hora do preparo? } \\
\text { Uso de Hipoclorito de Sódio específico? } \\
\text { Imersão total dos artigos e prolongamentos? } \\
\text { Imersão simultânea dos artigos? } \\
\text { Controle de tempo de imersão? } \\
\text { Retirada dos artigos com pegador específico e desinfetado? } \\
\text { Artigos secados com compressa estéril? } \\
\text { Uso de luvas de procedimento limpas? } \\
\text { Disposição dos artigos em cuba estéril e/ou desinfetada? } \\
\text { 4. Relativo ao embalo } \\
\text { Uso de embalagens plásticas individuais? } \\
\text { Embalagem lacrada? } \\
\text { Uso de luvas de procedimento limpas? } \\
\text { Contato dos artigos com a bancada de apoio? } \\
\text { Identificação externa do artigo e data do processo? } \\
\text { 5. Relativo ao acondicionamento } \\
\text { Acondicionado em área específica? } \\
\text { Controle de temperatura e umidade? }\end{array}$ & $\begin{array}{l}\text { ( ) } \operatorname{sim} \\
\text { ( ) } \operatorname{sim} \\
\text { ( ) } \operatorname{sim} \\
\text { ( ) } \operatorname{sim} \\
\text { ( ) } \operatorname{sim} \\
\text { ( ) } \operatorname{sim} \\
\text { ( ) } \operatorname{sim} \\
\text { ( ) } \operatorname{sim} \\
\text { ( ) } \operatorname{sim} \\
\text { ( ) } \operatorname{sim} \\
\text { ( ) } \operatorname{sim} \\
\text { ( ) } \operatorname{sim} \\
\text { ( ) } \operatorname{sim} \\
\text { ( ) } \operatorname{sim} \\
\text { ( ) } \operatorname{sim} \\
\text { ( ) } \operatorname{sim} \\
\text { ( ) } \operatorname{sim} \\
\text { ( ) } \operatorname{sim} \\
\text { ( ) } \operatorname{sim} \\
\text { ( ) } \operatorname{sim} \\
\text { ( ) } \operatorname{sim} \\
\text { ( ) } \operatorname{sim} \\
\text { ( ) } \operatorname{sim} \\
\text { ( ) } \operatorname{sim} \\
\text { ( ) } \operatorname{sim} \\
\text { ( ) } \operatorname{sim} \\
\text { ( ) } \operatorname{sim} \\
\text { ( ) } \operatorname{sim} \\
\text { ( ) } \operatorname{sim}\end{array}$ & $\begin{array}{l}\text { ( ) não } \\
\text { ( ) não } \\
\text { ( ) não } \\
\text { ) não } \\
\text { ( ) não } \\
\text { ( ) não } \\
\text { ( ) não } \\
\text { ( ) não } \\
\text { ( ) não } \\
\text { ( ) não } \\
\text { ( )não } \\
\text { ( ) não } \\
\text { ( ) não } \\
\text { ( ) não } \\
\text { ( ) não } \\
\text { ( ) não } \\
\text { ( ) não } \\
\text { ( ) não } \\
\text { ( ) não } \\
\text { ( ) não } \\
\text { ( ) não } \\
\text { ( ) não } \\
\text { ( ) não } \\
\text { ( ) não } \\
\text { ( ) não } \\
\text { ( ) não } \\
\text { ( ) não } \\
\text { ( ) não }\end{array}$ \\
\hline
\end{tabular}




\begin{tabular}{|c|c|}
\hline Prateleiras de material lavável? & ( ) não \\
\hline 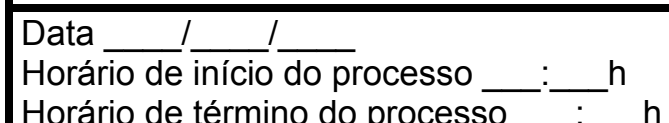 & Assinatura \\
\hline
\end{tabular}

Além dos registros de processos, a que se considerar a necessidade de implantação de um sistema de registro de avaliação periódica e validação das amostras encaminhadas para cultura direta. Neste sentido, propomos a adoção de uma ficha que considere os principais indicadores de qualidade do EAS, elaborados na forma de Manuais de Normas e Rotinas. A que se considerar que a existência destes manuais não refletirá em qualidade se os mesmos não estiverem em conformidade com as legislações sanitárias vigentes e não forem utilizados na íntegra.

TABELA 03 - Validação dos Processos de Limpeza e Desinfecção

Centro de Material e Esterilização

VALIDAÇÃO DOS PROCESSOS DE LIMPEZA E DESINFECÇÃO Artigos de Inaloterapia e Oxigenoterapia

\section{Parâmetros Gerais de Controle de Qualidade}

Manual de Normas e Rotinas de Controle de Qualidade da Água? Manual de Normas e Rotinas dos Processos de Limpeza e Desinfecção?

Manual de Normas e Rotinas da Central de Diluição de Germicidas? Manual de Normas e Rotinas Relacionadas ao Padrão de Tráfego? Manual de Normas e Rotinas de Biossegurança?

Manual de Normas e Rotinas do Serviço de Educação Continuada?

Padronização dos Insumos para Limpeza e Desinfecção?

\section{Seleção das Amostras}

\begin{tabular}{|c|c|c|c|}
\hline$\square$ Imediatamente & o Processo & $\square 14^{\circ} \mathrm{dia}$ & $\square 21^{\circ} \mathrm{dia}$ \\
\hline$\square$ Inaloterapia & $\square$ Oxigenoterapia & $\square$ Prolongamentos & $\square$ Circuitos \\
\hline $\mathrm{N}^{\circ}$ amostras & $\mathrm{N}^{\circ}$ amostras & $\mathrm{N}^{\circ}$ amostras & $\mathrm{N}^{\circ}$ amostras \\
\hline \multicolumn{4}{|c|}{ Resultado das Culturas } \\
\hline $\begin{array}{l}\mathrm{N}^{0} \text { Negativas } \\
\mathrm{N}^{0} \text { Positivas }\end{array}$ & $\begin{array}{l}\mathrm{N}^{\circ} \text { Negativas } \\
\mathrm{N}^{0} \text { Positivas }\end{array}$ & $\begin{array}{l}\mathrm{N}^{0} \text { Negativas } \\
\mathrm{N}^{0} \text { Positivas }\end{array}$ & $\begin{array}{l}N^{\circ} \text { Negativas } \\
N^{\circ} \text { Positivas }\end{array}$ \\
\hline $\begin{array}{l}\text { Microorganismo } \\
\text { Isolado }\end{array}$ & $\begin{array}{l}\text { Microorganismo } \\
\text { Isolado }\end{array}$ & $\begin{array}{l}\text { Microorganismo } \\
\text { Isolado }\end{array}$ & $\begin{array}{l}\text { Microorganismo } \\
\text { Isolado }\end{array}$ \\
\hline
\end{tabular}


Observações/considerações:

Data

Assinatura Responsável

Por último, a que se considerar a relevância do Serviço de Educação Continuada no processo de validação da limpeza e desinfecção dos artigos uma vez que a subjetividade das avaliações específicas de controle de qualidade aponta para o desenvolvimento de uma equipe técnica harmonizada com os objetivos do EAS, não se esgotando aqui as discussões a respeito de metodologias específicas como subsídio para a regulamentação das práticas no CME.

\section{REFERÊNCIAS}

BRASIL. Resolução de Diretoria Colegiada $\mathbf{n}^{\circ} \mathbf{5 0}$ (RDC) de 21 de fevereiro de 2002. Dispõe sobre regulamento técnico para planejamento, programação, elaboração e avaliação de estabelecimentos assistenciais de saúde. Disponível em: <http:// www.anvisa.gov.br> Acesso em: 28 out. 2002.

BRASIL. Orientações Gerais para Central de Esterilização. Ministério da Saúde. Secretaria de Assistência à Saúde. Série A Normas e Manuais Técnicos, n. 108. Brasília, 2001.

BRASIL. Portaria n. 2.616 de 12 de maio de 1998. Ministério da Saúde. Brasília, 1998.

BRASIL. Processamento de Artigos e Superfícies em Estabelecimentos de Saúde. Ministério da Saúde. 2. ed., Brasília, 1994.

BRASIL. Portaria n. 674 de 31 de dezembro de 1997. Ministério da Saúde. Brasília, 1987. 
BRASIL. Manual de Controle de Infecção Hospitalar. Centro de Documentação do Ministério da Saúde. Série A: Normas e Manuais Técnicos n. 16. Brasília, 1985.

BUENO, F. da S. Minidicionário da Língua Portuguesa. ed. rev. e atual. por Helena Bonito C. Pereira, Rena Signer. São Paulo: FTD: LISA, 1996.

CARDO, D. M.; DRAKE, A. Central Sterile Supply. In: MAYHALL, C. G. Hospital Epidemiology and Infection Control. William \& Wilkins, Baltimore, 1996.

FERNANDES, Antônio T. Infecção Hospitalar e suas interfaces na Área da Saúde. Vol. 1 e 2. São Paulo: Atheneu, 2000.

GIL, A. C. Como elaborar projetos de pesquisa. São Paulo: Atlas, 1996.

GUIA ELABORADO POR ENFERMEIROS BRASILEIROS. Recomendações práticas em processos de esterilização em estabelecimentos de saúde. Parte I : Esterilização a calor. São Paulo: Komedi, 2000.

MOURA, M. L. P. Gerenciamento da Central de Material e Esterilização para Enfermeiros, s.ed., 1996.

RODRIGUES, A. B. e cols. Central de Material e Esterilização: Rotinas Técnicas. Belo Horizonte, 1995.

SILVA, M. D'A. A.; RODRIGUES, L. A.; CEZARETTI, I. U. R. Estrutura Organizacional da Central de Material. In: Enfermagem na Unidade de Centro Cirúrgico. São Paulo: EPU/EDUSP, 1997.

SOBECC. Práticas Recomendadas da SOBECC. 1. ed., s.ed., Gestão 19992001. 